\title{
Functional and molecular alterations of the glomerular barrier in long-term diabetes in mice
}

\author{
M. Jeansson • A. Björnson Granqvist • \\ J. Sörensson Nyström • B. Haraldsson
}

Received: 20 December 2005 / Accepted: 2 May 2006 / Published online: 26 July 2006

(C) Springer-Verlag 2006

\begin{abstract}
Aims/hypothesis Despite the fact that diabetic nephropathy is an increasingly common disorder that may lead to uraemia, the underlying mechanisms are still poorly understood and there is no specific therapy. To clarify whether long-term diabetes alters glomerular size- or charge-selectivity or both, we studied non-obese diabetic mice for up to 40 weeks.

Materials and methods During the study period, spot urine was collected and blood pressure measured. At weeks 10 and 40 , the right kidney was isolated and perfused at $8^{\circ} \mathrm{C}$ to inhibit tubular function, allowing for analysis of glomerular selectivity with albumin and Ficoll clearance. The left kidney was removed for further investigation using electron microscopy and molecular biology. Real-time PCR with low-density arrays was done to evaluate renal cortex mRNA expression of proteoglycans and other components in the glomerular barrier. After 40 weeks of diabetes, kidneys showed morphological changes typical of diabetic complications.

Results At 40 weeks, the fractional clearance for negatively charged albumin was three times higher in the diabetic animals $(0.0160)$ than in controls $(0.0051, p<0.001)$, while fractional clearance for neutral Ficoll $35.5 \AA$ with a Stokes Einstein radius similar to that of albumin was unaffected. In
\end{abstract}

M. Jeansson $(\bowtie) \cdot$ A. B. Granqvist · J. S. Nyström

B. Haraldsson

Renal Center, Department of Nephrology,

Institute of Internal Medicine, Sahlgrenska Academy,

Bruna Straket 16,

SE-413 45 Gothenburg, Sweden

e-mail: marie.jeansson@kidney.med.gu.se addition, protein and mRNA levels for versican and decorin were downregulated after 40 weeks of diabetes.

Conclusions/interpretation We conclude that glomerular charge- but not size-selectivity was impaired in the diabetic animals with proteinuria. Also, glomerular components such as versican, decorin and fibromodulin were found to be downregulated after 40 weeks of diabetes.

Keywords Charge-selectivity · Cooled isolated perfused kidney · Decorin · Diabetic nephropathy · Versican
Abbreviations
cIPK cooled isolated perfused kidney
D10 10 weeks of diabetes
D40 40 weeks of diabetes
GBM glomerular basement membrane
LDA low-density array
NOD non-obese diabetic

\section{Introduction}

Worldwide, diabetic nephropathy is the most common cause of chronic kidney disease. Albuminuria is a hallmark of diabetic nephropathy, reflecting impairment of the glomerular capillary wall. Under normal conditions, the glomerular barrier restricts the passage of macromolecules such as albumin, while it is highly permeable to water and small solutes. The underlying mechanisms leading to proteinuria are still poorly understood, although the importance of the podocyte for glomerular integrity has been clearly documented [1-3]. Consequently, there is no specific therapy for diabetic nephropathy. 
It is generally agreed that the glomerular barrier has both size- and charge-selective properties. However, the structures responsible for the permselective properties are under debate. For a long time the glomerular basement membrane (GBM) has been considered to be the main barrier for filtration. More recently, focus has shifted to the podocytes, since several novel proteins in the podocyte slit diaphragm have been found to be important for the barrier function [1-3]. In addition, we have suggested a role for the glomerular endothelial cell glycocalyx [4-10], an idea supported also by others $[11,12]$.

Previous studies have suggested that proteinuria in diabetes originates from alteration of either size- [13-16] or charge-selectivity [13, 17-21] or both [22, 23]. Much of the controversy over this issue may be due to methodological differences and limitations. Thus, in vivo studies of proteinuria in patients or animals all have the major disadvantage that proteins can be reabsorbed, secreted or degraded in the tubules. Consequently, the protein concentration in the final urine may differ considerably from that of primary urine. To overcome these limitations, one may use the inert polysaccharides dextran or Ficoll as markers instead of albumin. Alternatively, the tubular processes may be inhibited by toxins [24], but such drugs seem to affect permeability per se [25]. At present, one of the most reliable estimates of glomerular filtration is obtained by using the cooled isolated perfused kidney (cIPK) model, either in rats $[4,8,26]$ or in mice [9].

We have recently shown that human glomerular endothelial cells produce several different proteoglycans [10] and that hyaluronan and/or chondroitin sulphate in the glomerular endothelial cell glycocalyx are important to maintain charge-selective properties in the barrier [9]. In diabetic nephropathy, studies have suggested that decreased synthesis of heparan sulphate proteoglycans [27-30] such as perlecan [31] is the reason for altered barrier function. Perlecan and agrin are the major proteoglycans in the GBM, both carrying heparan sulphate. However, genetically modified mice lacking heparan sulphate chains on perlecan did not develop proteinuria [32]. Thus, studies concerning the role of proteoglycans in normal and diabetic kidneys are still incomplete. The aim of this study was to assess functional, molecular and morphological changes of the glomerular barrier in non-obese diabetic (NOD) mice after 10 and 40 weeks of diabetes.

\section{Materials and methods}

Animals and animal treatment

Experiments were performed in female NOD mice (M\&B, Stensved, Denmark), a strain that spontaneously develops insulin-dependent diabetes mellitus. The mice were kept on standard chow and had free access to water prior to the experiments. The local ethics review committee approved the experiments.

Diabetic NOD mice, aged 10-12 weeks at arrival, were observed for 10 weeks (D10) and 40 weeks (D40) while receiving insulin s.c. via implants (Linbit; Linshin Canada, ON, Canada) to maintain their blood glucose between 20 and $33 \mathrm{mmol} / \mathrm{l}$. At the end of the study, the left kidney was removed for electron microscopy and molecular biology, and the right kidney subjected to the cIPK procedure. NOD mice at 25 weeks of age, which had not yet developed diabetes at the breeders (blood glucose $<10 \mathrm{mmol} / \mathrm{l}$ ), were used as controls and observed 1 week prior to the cIPK study.

Urine samples were collected once for controls or every third week for diabetic mice, and blood glucose (One Touch Ultra; Johnson \& Johnson, Stockholm, Sweden) and mouse weight were recorded. Systolic blood pressure was measured with a tail-cuff (Harvard Apparatus, Edenbridge, UK) on two consecutive days every third week.

Urinary albumin and creatinine

Albumin was determined in spot urine using ELISA (Bethyl Laboratories, Montgomery, TX, USA) with mouse albumin (ICN Biomedicals, Irvine, CA, USA) as standard. All urine samples were corrected for the urinary creatinine concentration measured with a creatinine assay (Sigma Diagnostics, Sigma-Aldrich, Dorset, UK).

\section{Isolated perfused kidneys at $8^{\circ} \mathrm{C}(\mathrm{cIPK})$}

Anaesthesia was induced and continued by inhalation of isoflurane $(2-3 \% \mathrm{v} / \mathrm{v}$; Isoflurane; Pharmacia \& Upjohn, Stockholm, Sweden) mixed with air $(\sim 1 / 1 / \mathrm{min})$ in an isoflurane vaporiser (Ohmeda Isotec 5; Simtec Engineering, Askim, Sweden). The body temperature of the mouse was kept at $37^{\circ} \mathrm{C}$. The carotid artery was cannulated with a PE10 cannula connected to a pressure transducer (PVB Medizintechnik GmbH, Kirchenseeon, Germany) for registration of arterial pressure. The mouse was eviscerated and the intestines removed. A cannula (PE-25) was put into the bladder for collection of urine. The left renal vein and artery were ligated and the left kidney was removed for molecular biology and electron microscopy. The aorta and caval vein were clamped distal to the renal arteries and the aorta was cannulated in a retrograde direction with a T-tube (PE-25), connected to a pressure transducer. The clamp was removed, allowing perfusion of the right kidney by means of a pulsatile pump (Ismatec IPC, Zurich, Switzerland). The aorta was then ligated proximal to the renal arteries and the caval vein was opened for venous outflow distal to the renal 
arteries. The animal was killed by cutting the heart ventricles open. After a short period of equilibration, urine samples were collected and weighed. Great care was taken not to touch the kidneys and to provide adequate perfusion with either blood or perfusate during the preparation procedure. The temperature of the perfusate was kept at $8^{\circ} \mathrm{C}$ in order to inhibit tubular function as well as energy consumption. Arterial pressure and urine weight changes were monitored by computer using AcqKnowledge v 3.7.3 (Biopac Systems Inc., Goleta, CA, USA) computer software.

\section{Perfusate for cIPK}

Perfusate was prepared using a modified Tyrode solution with human serum albumin (18 g/l; Immuno, Vienna, Austria), ${ }^{51} \mathrm{Cr}$-EDTA and FITC-labelled Ficoll in the size range 12-70 $\AA$. The solution had the following composition: $113 \mathrm{mmol} / \mathrm{l} \mathrm{NaCl}, 4.3 \mathrm{mmol} / \mathrm{l} \mathrm{KCl}, 2.5 \mathrm{mmol} / 1 \mathrm{CaCl}_{2}$, $0.8 \mathrm{mmol} / 1 \mathrm{MgCl}_{2}, 25.5 \mathrm{mmol} / 1 \mathrm{NaHCO}_{3}, 0.5 \mathrm{mmol} / \mathrm{l}$ $\mathrm{NaH}_{2} \mathrm{PO}_{4}, 5.6 \mathrm{mmol} / 1$ glucose, $0.9 \mathrm{mmol} / 1$ nitroprusside (Merck, Darmstadt, Germany), $10 \mathrm{mg} / 1$ furosemide, $200 \mathrm{mg} / 1$ FITC-labelled Ficoll (TdB Consultancy AB, Uppsala, Sweden), $0.16 \mathrm{MBq} / 1{ }^{51} \mathrm{Cr}$-EDTA (Amersham Pharmacia Biotech, Bucks, UK). The perfusate ( $\mathrm{pH} 7.4)$ was protected from light and gassed with $5 \% \mathrm{CO}_{2}$ in $\mathrm{O}_{2}$.

\section{cIPK data analysis}

Perfusate and urine samples from cIPK experiments were analysed for ${ }^{51} \mathrm{Cr}$-EDTA in a gamma counter (Cobra AutoGamma Counting systems; Packard Instrument Company, Meriden, CT, USA) and human serum albumin by an immunoturbidimetric assay (Triolab, Mölndal, Sweden). Glomerular filtration rate was calculated from the urine: perfusate concentration ratios for ${ }^{51} \mathrm{Cr}$-EDTA multiplied by urine flow. Fractional clearance for a solute is given by its urine concentration divided by plasma concentration corrected for the residual tubular reabsorption (approximately 1.15) using ${ }^{51} \mathrm{Cr}$-EDTA or the smallest Ficolls.

\section{Analysis of Ficoll}

The fractional clearance for different radii of FITC-Ficoll was calculated by subjecting perfusate and urine samples to gel filtration (TSK-gel G4000 $\mathrm{PW}_{\mathrm{XL}}$; Tosoh Bioscience, Stuttgart, Germany) and detection of fluorescence (Dionex fluorimeter RF-2000; Dionex Softron, Gynkotek, Germering, Germany) using Chromeleon (Gynkotek) software. A $0.05 \mathrm{~mol} / 1$ phosphate buffer with $0.15 \mathrm{~mol} / \mathrm{l} \mathrm{NaCl}(\mathrm{pH} 7.0)$ was used as eluent. A volume of $5 \mu \mathrm{l}$ from each sample was analysed at an excitation wavelength of $492 \mathrm{~nm}$ and an emission wavelength of $560 \mathrm{~nm}$. The flow rate $(0.5 \mathrm{ml} / \mathrm{min})$ and the sampling frequency $(1 / \mathrm{s})$ were maintained constant during the analysis and so were pressure $(\sim 2 \mathrm{MPa})$ and temperature $\left(8^{\circ} \mathrm{C}\right)$.

The gel-membrane model

According to the gel-membrane model, the glomerular barrier is simplified to one charge-selective barrier (gel) and one size-selective barrier (membrane) in series. The gel is in contact with plasma and contains fixed negative charges, reducing the concentration of anionic solutes, such as albumin. The membrane exerts size-selective properties. The concentrations of a solute in the urine will depend on the effects of these two barriers as outlined below. Sizeselective properties can be described by using a two-pore model with experimental fractional clearances for Ficolls with a molecular radius range of $12-70 \AA$. In brief, the exchange was estimated using the following parameters: the functional small- and large-pore radii, the large-pore fraction of the glomerular filtrate, and the unrestricted area divided by diffusion distance [33]. By using a non-linear regression analysis and a previously defined set of physiological equations [8], model parameters were fitted to the experimental fractional clearances for neutral Ficolls (12-70 $\AA$ ). Non-linear flux equations were used to calculate net fluxes of fluid and solutes for the small- and large-pore pathways individually. For calculation of charge-selectivity, the fractional clearances for the negatively charged albumin and its neutral counterpart of the same Stokes Einstein radius, Ficoll $35.5 \AA$, were compared. For further details on calculations, see Ohlson et al. [8].

\section{Real-time PCR}

RNA was prepared from fresh frozen renal cortex using the Qiagen mini kit (Roche Diagnostics, Bromma, Sweden). The concentration and quality of the RNA were evaluated by the Agilent 2100 bioanalyser (Nano LabChip; Agilent Technologies, Waldbronn, Germany). Synthesis of cDNA was carried out using $1 \mu \mathrm{g}$ of the RNA in an avian myeloblastosis virus reverse transcriptase (AMV RT) buffer with AMV RT, dNTP (deoxy-CTP, -GTP, -TTP and -ATP), random hexamers and RNase inhibitor (all reagents from Roche Diagnostics) in a final volume of $20 \mu \mathrm{l}$. The reaction conditions were $5 \mathrm{~min}$ at $25^{\circ} \mathrm{C}$ and $50 \mathrm{~min}$ at $42^{\circ} \mathrm{C}$, followed by $5 \mathrm{~min}$ at $70^{\circ} \mathrm{C}$. The mRNA level of each target gene (Table 1) was quantified by real-time PCR on an ABI Prism 7900 Sequence Detection system (Taqman; Applied Biosystems, Foster City, CA, USA) using the low-density array (LDA) or 96-well plates (for TGF- $\beta_{1}$ ). The PCR was carried out in a reaction mix containing 50 ng sample cDNA and Taqman universal PCR master mix (containing $\mathrm{MgCl}_{2}$, dUTP, dATP, dCTP, dGTP, Taq Gold polymerase and AmpEraseUNG). The AmpEraseUNG was activated before 
Table 1 Targets analysed by real-time PCR

\begin{tabular}{|c|c|c|c|c|}
\hline \multirow[t]{2}{*}{ Coded protein } & \multirow[t]{2}{*}{ Accession no. } & \multirow[t]{2}{*}{ Protein description } & \multicolumn{2}{|c|}{ Change compared with control } \\
\hline & & & D10 & $\mathrm{D} 40$ \\
\hline $18 \mathrm{~S}$ & - & Endogenous control & & \\
\hline$\beta$-Actin & NM_007393 & Endogenous control & & \\
\hline Biglycan & NM_007542 & CS/DS, SLRP, secreted & - & - \\
\hline Decorin & NM_007833 & CS/DS, SLRP, secreted & - & $\downarrow$ \\
\hline Fibromodulin & NM_021355 & KS, SLRP, secreted & - & $\downarrow$ \\
\hline Versican & D28599 & CSPG, secreted & $\downarrow$ & $\downarrow$ \\
\hline Perlecan & M77174 & HS/CSPG, secreted & - & - \\
\hline Glypican-1 & NM_016696 & HSPG, GPI-anchored & - & - \\
\hline Glypican-4 & NM_008150 & HSPG, GPI-anchored & - & - \\
\hline Syndecan-1 & NM_011519 & HSPG, membrane-bound & - & - \\
\hline Syndecan-4 & NM_011521 & HSPG, membrane-bound & - & - \\
\hline Nephrin & NM_019459 & Podocyte slit & - & - \\
\hline Podocin & NM_130456 & Podocyte slit & - & - \\
\hline $\mathrm{PKC} \delta$ & NM_011103 & Protein kinase $\mathrm{C}$ & - & - \\
\hline MMP-9 & NM_013599 & Matrix metalloprotease-9 & - & - \\
\hline TGF- $\beta_{1}$ & NM_011577 & Transforming growth factor $\beta_{1}$ & - & - \\
\hline
\end{tabular}

$\downarrow$ downregulated expression; - unchanged expression CS Chondroitin sulphate, $D S$ dermatan sulphate, GPI glycosyl-phosphatidylinositol, $H S$ heparan sulphate, $K S$ keratin sulphate, $P G$ proteoglycan, $S L R P$ small leucine-rich proteoglycan, CSPG chondroitin sulphate proteoglycan, $H S P G$ heparan sulphate proteoglycan
USA) for decorin, podocin and TGF- $\beta_{1}$ and on NuPAGE $3-8 \%$ Tris-acetate gels (Novex) for versican. After electrophoresis the proteins were transferred to polyvinylidene difluoride membranes (decorin, podocin and TGF- $\beta_{1}$ ) or nitrocellulose membrane (versican). Membranes were blocked and immunological detection was done using the following primary antibodies: rabbit anti-versican (kind gift from Dr D. Zimmerman, Department of Pathology, Zurich, Switzerland), rabbit anti-podocin (Sigma-Aldrich), rabbit anti-decorin, rabbit anti-TGF- $\beta_{1}$ and rabbit anti-GAPDH (all from Abcam Ltd, Cambridge, UK) as loading control. Horseradish peroxidase-conjugated anti-rabbit IgG (Amersham) was used to visualise immunoreactive bands with enhanced chemoluminescence (ECL plus; Amersham) in a CCD camera (LAS1000; Fujifilm, Tokyo, Japan).

Immunohistochemistry was performed on acetone-fixed $4-\mu \mathrm{m}$ fresh-frozen tissue sections. Sections for versican staining were pretreated with $0.5 \mathrm{U} / \mathrm{ml}$ chondroitinase $\mathrm{ABC}$ (Sigma-Aldrich). Double-staining was performed with primary antibodies towards versican (Chemicon Europe, Hants, UK) and decorin as described above, together with the endothelial cell marker goat anti-von Willebrand factor (Santa Cruz Biotechnology Inc., Santa Cruz, CA, USA).

\section{Morphological estimations}

GBM thickness was measured in electron micrographs where the thickness was defined as the distance between the podocyte foot process and the corresponding endothelial cell. To ensure proper cross-sectioning, a slit diaphragm between the foot processes had to be visible as well as a single layer of endothelial cells. Sclerotic areas were 


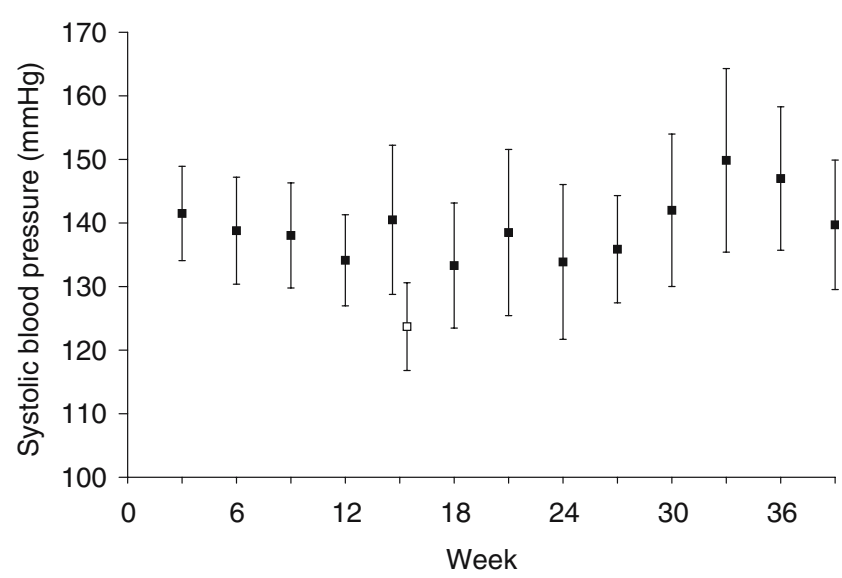

Fig. 1 Means and 95\% CIs for systolic blood pressure estimated with tail-cuff for control (open squares, $n=10$ ) and diabetic (black squares, $n=7-23$ ) mice. Until week 9 both D10 and D40 are included

visualised with periodic acid-Schiff staining on $4-\mu \mathrm{m}$ cryosections on light microscopy. A microscopic image for each glomerulus was evaluated in Adobe Photoshop 7.0. The glomerular interface was marked, giving the glomerular area, and the sclerotic area was estimated by colour tracing.

\section{Statistics}

Results are presented as means and $95 \%$ CIs. Variables were tested for uneven distribution (skewness $>2$ SDs) and unequal variance. Logarithmic values were used for variables with uneven distribution, i.e. GFR, fractional clearance for albumin, Ficoll $35.5 \AA$ and Ficoll $55 \AA$, large-pore fraction of the glomerular filtrate, glomerular area, sclerosis/glomerulus, GBM thickness, albumin:creatinine ratio, and mRNA expression. Statistical comparisons were made with controls using one-way ANOVA and a post-hoc Dunnett test. A value $p<0.05$ was considered statistically significant.

\section{Results}

General

The mice had a mean body weight of $26.9 \mathrm{~g}$ (26.0-27.8), $29.2 \mathrm{~g}$ (28.4-29.9) and $28.9 \mathrm{~g} \mathrm{(27.3-30.4)} \mathrm{for} \mathrm{controls,} \mathrm{D10}$ and D40, respectively. No increase in systolic blood pressure over time could be seen. Diabetic animals had a systolic blood pressure of $\sim 140 \mathrm{mmHg}$ throughout the study (Fig. 1). The blood glucose was $12.4 \mathrm{mmol} / \mathrm{l}$ (7.517.3), $24.3 \mathrm{mmol} / 1(20.5-28.1)$, and $24.5 \mathrm{mmol} / 1$ (22.826.1) for controls, D10 and D40, respectively.

Diabetic mice showed a significant increase in glomerular surface area and periodic acid-Schiff-positive staining as estimated with light microscopy. Using transmission electron microscopy the GBM thickness was measured and found to be significantly increased in both diabetic groups compared with controls $(p<0.001)$. In addition, D40 increased the kidney weight significantly $(p<0.01)$. Data regarding glomerular morphology are summarised in Table 2 and GFRs from the cIPK are described in Table 3.

Permselectivity of the glomerular barrier

Albuminuria was constant and similar for controls and diabetic animals until week 24 . Thereafter, diabetic animals showed a significant increase in albumin:creatinine ratio $(p<0.001$, Fig. 2).

The fractional clearance for albumin in the cIPK was found to be significantly increased at D40 $(p<0.001$, Table 3). There was no difference in fractional clearances for Ficoll $35.5 \AA$, the neutral counterpart of albumin, compared with controls (Table 3$)$. The fractional clearances for all Ficoll sizes (12-70 $\AA$ ) are shown in Fig. 3. To further describe the glomerular barrier, mathematical estimations were performed using the data above and the fractional clearances for all Ficoll sizes $(12-70 \AA)$ in a gel-membrane model, including two-pore analysis and calculations of glomerular charge density. The two-pore analysis showed no increase in small- or large-pore radii in diabetes, thus reflecting unaltered size-selectivity (Table 4 ). The radius was $46.2-46.8 \AA$ for the small pore and $110-173 \AA$ for the less frequent large pore. There was an approximately $40 \%$ reduction in charge density in the glomerular barrier from $41.4 \mathrm{mEq} / \mathrm{l}(30.1-52.8)$ in controls to $25.6 \mathrm{mEq} / 1$ (20.6$30.7)$ in the D40 group $(p<0.001$, Table 4$)$.

Expression of mRNA and proteins

Real-time PCR revealed a significant downregulation in the renal cortex of several genes in diabetic compared with control animals. At D10, versican mRNA was significantly

Table 2 Diabetic nephropathy

\begin{tabular}{lllll}
\hline & Glomerular area $\left(\mu \mathrm{m}^{2}\right)$ & Sclerosis/glomerulus $(\%)$ & GBM thickness $(\mathrm{nm})$ & Kidney weight/body weight $(\%)$ \\
\hline Control & $4,966(4,658-5,294)$ & $0.002(0.0003-0.008)$ & $169(164-175)$ & $0.82(0.71-0.94)$ \\
D10 & $5,428(5,173-5,695)$ & $0.160(0.084-0.305)^{\mathrm{a}}$ & $189(180-198)^{\mathrm{a}}$ & $0.95(0.83-1.07)$ \\
D40 & $6,142(5,855-6,444)^{\mathrm{a}}$ & $0.599(0.413-0.869)^{\mathrm{a}}$ & $248(233-264)^{\mathrm{a}}$ & $1.04(0.95-1.13)^{\mathrm{a}}$ \\
\hline
\end{tabular}

Means and $95 \%$ CIs. ${ }^{a} p<0.001$ compared with control 
Table 3 GFR and fractional clearances for albumin, Ficoll $35.5 \AA$ and Ficoll $55 \AA$ in the cIPK

\begin{tabular}{lclll}
\hline & $\theta_{\text {Albumin }}\left(\times 10^{-3}\right)$ & $\theta_{\text {Ficoll 35.5 } \AA}\left(\times 10^{-3}\right)$ & $\theta_{\text {Ficoll 55 } \AA}\left(\times 10^{-3}\right)$ & $\mathrm{GFR}_{\left(\mathrm{ml} \cdot \mathrm{min}^{-1} \cdot 100 \mathrm{gbw}^{-1}\right)}$ \\
\hline Control $(n=6)$ & $5.1(3.1-7.8)$ & $84(70-102)$ & $5.1(1.6-15.8)$ & $0.051(0.026-0.097)$ \\
D10 $(n=7)$ & $2.7(1.4-5.0)$ & $72(55-95)$ & $2.7(1.0-7.4)$ & $0.137(0.068-0.273)^{\mathrm{b}}$ \\
D40 $(n=8)$ & $16.0(10.8-23.8)^{\mathrm{a}}$ & $84(78-91)$ & $3.7(1.7-8.2)$ & $0.078(0.050-0.123)$ \\
\hline
\end{tabular}

Means and $95 \%$ CIs. $\theta$ Fractional clearance, $g b w$ gram body weight

${ }^{\mathrm{a}} p<0.001,{ }^{\mathrm{b}} p<0.05$ compared with control

downregulated $(p<0.01)$ and decorin tended to be upregulated (not significant). In addition, D40 downregulated mRNA for versican $(p<0.05)$, decorin $(p<0.01)$ and fibromodulin $(p<0.01$, Fig. 4, Table 1$)$. The mRNA regulation of decorin and versican was confirmed at the protein level by western blotting and their localisation in the glomerulus was investigated by immunohistochemistry (Fig. 5). In addition, we found no regulation of TGF- $\beta_{1}$ and podocin mRNA or protein (protein data not shown).

\section{Discussion}

In this study, we present the most extensive analysis to date of glomerular size- and charge-selectivity in mice with long-term diabetes. The functional alterations behind albuminuria were further examined by observing the gene expression of components of the glomerular barrier. Our main findings are as follows. Firstly, albuminuria in diabetic nephropathy is a consequence of altered chargeand not size-selectivity, as revealed by the gel-membrane model. Thus, the fractional clearance for neutral Ficolls of 12-70 $\AA$ was not affected by diabetes, whereas the clearance for albumin was raised threefold. Secondly, versican was significantly downregulated at D10 and D40. In addition, decorin and fibromodulin were significantly

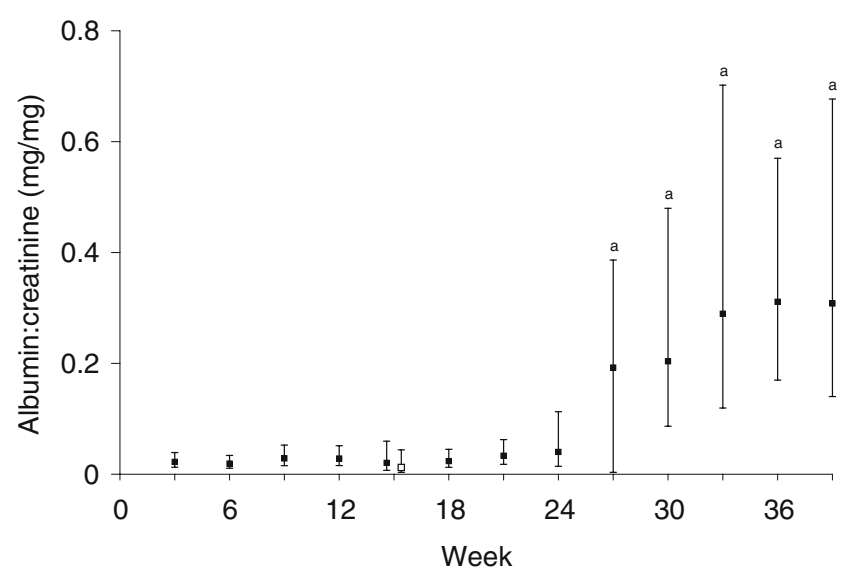

Fig. 2 Means and 95\% CIs for albumin:creatinine ratio for control (open squares, $n=10$ ) and diabetic (black squares, $n=7-23$ ) mice. Until week 9 both D10 and D40 are included. ${ }^{\mathrm{a}} p<0.001$ compared with control downregulated at D40 (Fig. 4, Table 1), i.e. when there was significant albuminuria.

In the NOD mouse, which is an established model of spontaneous insulin-dependent diabetes mellitus [34, 35], morphological changes and temporary hyperfiltration at D10 $[36,37]$ preceded the albuminuria that, in our hands, was apparent after 27 weeks. In humans, diabetic nephropathy is a late complication occurring progressively in susceptible patients after 15-30 years of diabetes, which probably corresponds to $25-30$ weeks in mice when considering their shorter lifespan.

Several previous papers have described glomerular filtration of proteins in vivo and interpreted the results in terms of size- and/or charge-selectivity. Albeit an attractive approach, in vivo studies of proteinuria in patients or animals all have the major disadvantage that proteins can be reabsorbed, secreted or degraded in the tubules, thus underestimating the filtered albumin. Since tubular modification of the primary urine is dependent on molecular size, charge and configuration, it is difficult to predict the final composition of the urine. Furthermore, diabetic patients and animal models of diabetes have been shown to have a clear reduction in the capacity of the proximal tubule to reabsorb albumin [38]. As our results show, this will give an apparently larger diabetic effect on albumin filtration in vivo than in the cIPK model. Cooling the kidneys, during the perfusion, inhibits tubular function $[39,40]$ and protease activity, thus giving a primary urine without tubular modifications. To be fair, the isolated perfused kidney model also has certain limitations and the number of large pores seems to be higher than in vivo. This, however, does not affect our conclusions based on differences between the experimental groups.

In our study, there was an increased albumin clearance without any change in Ficoll clearance, indicating glomerular charge-selectivity impairment. The results regarding pore sizes and charge density in controls are well in accord with previous studies in our laboratory on rats $[8,25,41,42]$ and mice [9], both in vivo and in the cIPK model. The fractional clearance for Ficolls larger than $\sim 50 \AA$ is approximately one order of magnitude larger in the cIPK compared with in vivo. This probably reflects an increased number of large pores following the isolation procedure [9]. However, all conclusions are based on differences between 


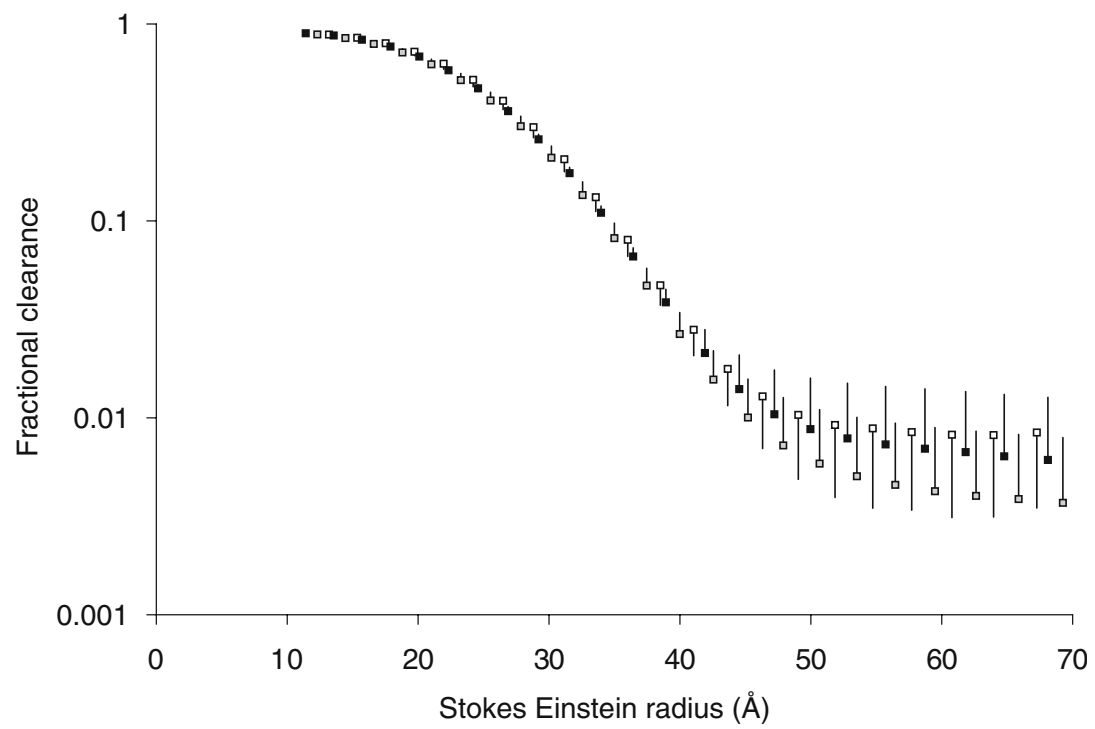

Fig. 3 Means and 95\% CIs for neutral Ficolls for controls (white squares, $n=6$ ), D10 (grey squares, $n=7$ ) and D40 (black squares, $n=8$ ). Only every tenth value and one bar for the $95 \%$ CI are shown for the sake of clarity. Please note the logarithmic scale

the three experimental groups subjected to the same procedure. Therefore, the changes observed in the diabetic animals reflect true alterations of the glomerular barrier.

Proteinuria in diabetes has been suggested to originate from alteration in either size- [13-16] or charge-selectivity $[13,17-21]$ or both $[22,23]$. As mentioned above, our data support the view that the charge density is reduced in diabetic nephropathy. There was a tendency for reduced size-selectivity but the increased number of large pores did not reach statistical significance. There are several reasons for the discrepancy in the literature regarding charge- and size-selectivity in diabetic nephropathy. Firstly, it may be due to differences in methodology, since measurements of glomerular permeability in vivo and in vitro have limitations as discussed above. Secondly, there may be species differences or differences due to the mechanisms behind the diabetes. Finally, the studies differ in severity of disease and time of observation. In the present long-term study in mice, proteinuria was caused by a reduced glomerular charge density with no significant change in size-selectivity.

The second objective of this study was to couple the observed functional changes to molecular alterations. Thus, we investigated two podocyte-specific proteins (nephrin and podocin) together with proteoglycan core proteins, TGF- $\beta_{1}$, protein kinase $C$ and matrix metalloprotease-9. The reason for our interest in proteoglycans is that they seem to play a crucial role in the microvascular permeability in all organs, including the kidney $[9,43]$. One of the most prominent changes induced by diabetes was the decreased expression of versican, decorin and fibromodulin. Versican is an extracellular matrix proteoglycan with chondroitin sulphate chains that are able to bind hyaluronic acid [44]. We have recently found it to be expressed by human glomerular endothelial cells [10] and versican is most likely a component of the endothelial cell glycocalyx. Furthermore, in previous studies we have shown that digestion of hyaluronic acid and/or chondroitin sulphate in the glomerular endothelial cell glycocalyx increases the fractional clearance for albumin $[9,43]$. Thus, downregulation of the highly negatively charged versican may cause altered glomerular endothelial cell glycocalyx composition and reduced charge-selectivity. However, versican was also downregulated at D10, where the fractional clearance for albumin was unaltered. Thus, further studies are needed to explore the role of versican in diabetic nephropathy and other glomerular disorders.

Table 4 Glomerular permselectivity estimated with the gel-membrane model, which includes two-pore analysis and calculation of charge density

\begin{tabular}{llllll}
\hline & Small-pore radius $(\AA)$ & Large-pore radius $(\AA)$ & $f_{\mathrm{L}}(\%)$ & $\begin{array}{l}A_{0} / \Delta_{X} \\
\left(\times 10^{-3} \mathrm{~cm}\right)\end{array}$ & Charge density $(\mathrm{mEq} / 1)$ \\
\hline Control $(n=6)$ & $46.8(45.6-47.9)$ & $167(119-228)$ & $0.42(0.18-0.96)$ & $21.0(0-43.9)$ & $41.4(30.1-52.8)$ \\
D10 $(n=7)$ & $46.3(45.2-47.4)$ & $108(86-134)^{\mathrm{a}}$ & $0.68(0.37-1.25)$ & $45.8(22.0-69.6)$ & $47.1(41.8-52.4)$ \\
$\operatorname{D} 40(n=8)$ & $46.2(45.4-47.0)$ & $118(86-161)$ & $0.62(0.38-1.01)$ & $19.4(11.2-27.6)$ & $25.6(20.6-30.7)^{\mathrm{b}}$ \\
\hline
\end{tabular}

Means and $95 \%$ CIs. $A_{0} / \Delta_{X}$ Unrestricted pore area divided by diffusion distance, $f_{\mathrm{L}}$ Large-pore fraction of the glomerular filtrate ${ }^{\mathrm{a}} p<0.05,{ }^{\mathrm{b}} p<0.001$ compared with control 


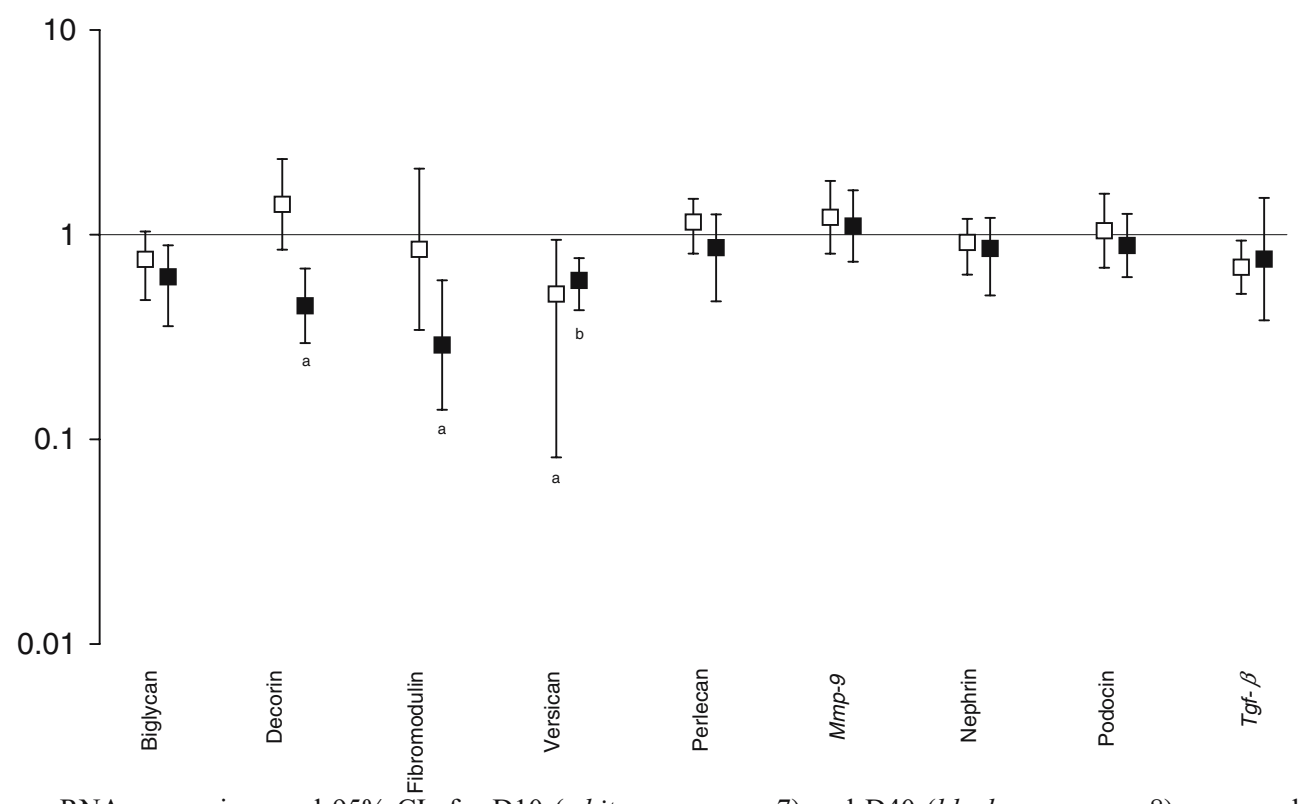

Fig. 4 The relative mRNA expressions and 95\% CIs for D10 (white squares, $n=7$ ) and D40 (black squares, $n=8$ ) compared with controls (1, $n=10)$. Please note the logarithmic scale. ${ }^{\mathrm{a}} p<0.01,{ }^{\mathrm{b}} p<0.05$. Mmp-9, matrix metalloprotease- 9 ; $\mathrm{Tg} f-\beta$, transforming growth factor

Our finding of a downregulation of the decorin core protein at $\mathrm{D} 40$ is consistent with the notion that this protein binds and neutralises extracellular TGF- $\beta$, thus antagonis- ing the prosclerotic effect of this cytokine $[45,46]$. The biological functions of fibromodulin are largely unknown; however, fibromodulin also binds to active TGF- $\beta$ [47].
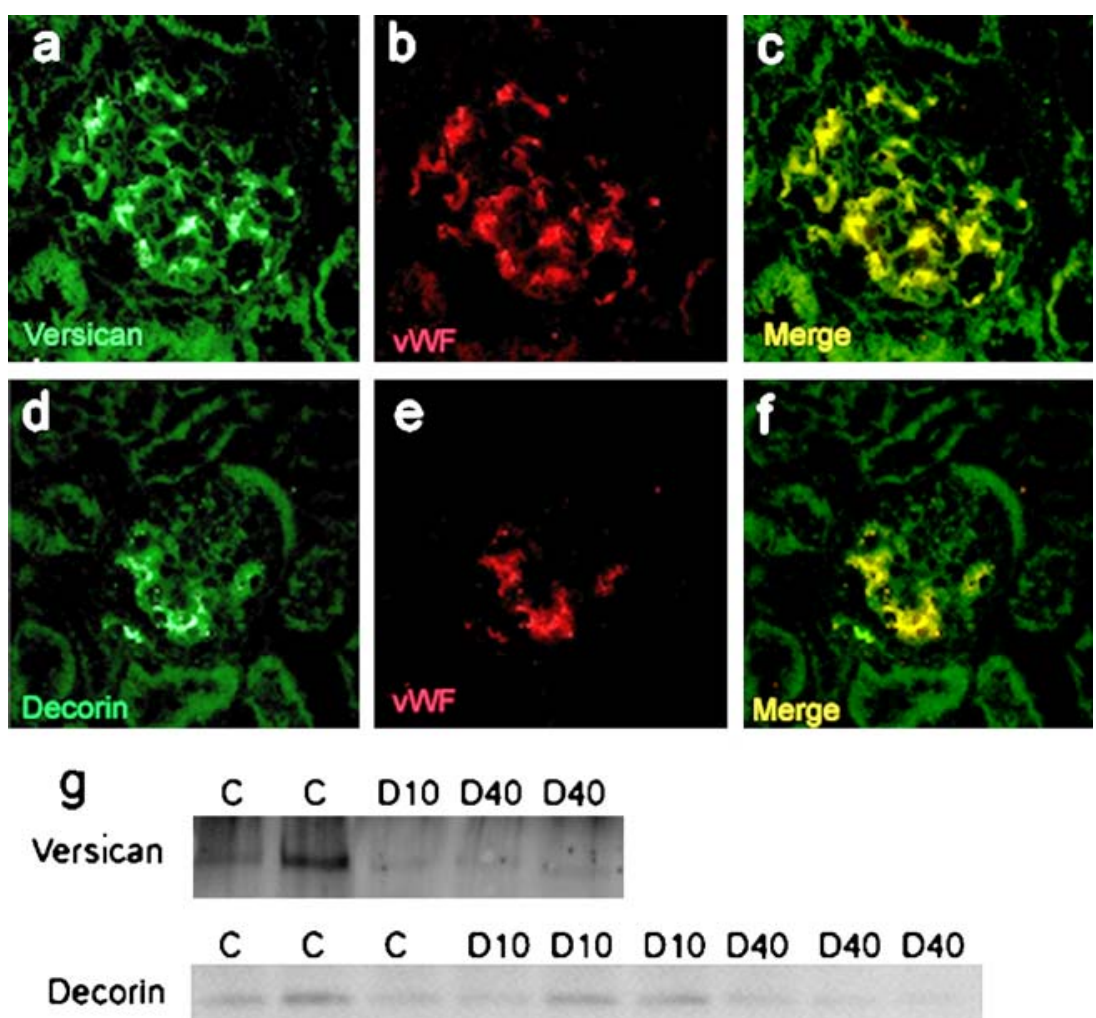

Fig. 5 Immunohistochemical localisation of proteins in the glomerulus from controls. a Stained for versican and (b) co-stained for the endothelial cell marker von Willebrand factor $(v W F)$. d Stained for decorin and (e) co-stained for von Willebrand factor. c, f Merged version of images in same row. $\mathbf{g}$ Western blots for versican and decorin 
Previous studies have reported an upregulation of decorin mRNA in the early phase (1-6 weeks) of diabetes in mice [48]. Indeed, at D10 we observed a tendency towards an upregulation of decorin (Fig. 4) and the changed decorin expression corresponds with changes in the fractional clearance for albumin. However, data in the literature regarding decorin expression in long-term diabetes are incomplete. In this study, we could not find any changes in mRNA and protein levels of TGF- $\beta_{1}$. Therefore, in these animals, proteinuria and GBM thickening seem to be mediated through a different pathway than TGF- $\beta$.

In summary, this study reveals that diabetic nephropathy alters the composition of the glomerular barrier, thus leading to reduced charge-selectivity and proteinuria. Versican is markedly downregulated in diabetic animals. In diabetes with proteinuria, versican, decorin and fibromodulin were found to be downregulated. Our findings support the idea that proteinuria in diabetic nephropathy is due primarily to altered charge-selectivity. This suggests that diabetic nephropathy may be treated by interfering with proteoglycan synthesis and degradation.

Acknowledgements Technical assistance by E. Roos is gratefully acknowledged. This study was supported by the Swedish Medical Research Council 9898, the Knut and Alice Wallenberg Research Foundation, the IngaBritt and Arne Lundbergs Research Foundation, the National Association for Kidney Diseases, the Swedish Diabetes Association Research Foundation, the John and Brit Wennerströms Research Foundation and Sahlgrenska University Hospital Grant LUA-7545.

\section{References}

1. Shih NY, Li J, Cotran R, Mundel P, Miner JH, Shaw AS (2001) $\mathrm{CD} 2 \mathrm{AP}$ localizes to the slit diaphragm and binds to nephrin via a novel C-terminal domain. Am J Pathol 159:2303-2308

2. Ruotsalainen V, Ljungberg P, Wartiovaara J et al (1999) Nephrin is specifically located at the slit diaphragm of glomerular podocytes. Proc Natl Acad Sci 96:7962-7967

3. Roselli S, Gribouval O, Boute N et al (2002) Podocin localizes in the kidney to the slit diaphragm area. Am J Pathol 160:131-139

4. Sörensson J, Ohlson M, Lindström K, Haraldsson B (1998) Glomerular charge selectivity for horseradish peroxidase and albumin at low and normal ionic strengths. Acta Physiol Scand 163:83-91

5. Haraldsson B, Sorensson J (2004) Why do we not all have proteinuria? An update of our current understanding of the glomerular barrier. News Physiol Sci 19:7-10

6. Hjalmarsson C, Johansson BR, Haraldsson B (2004) Electron microscopic evaluation of the endothelial surface layer of glomerular capillaries. Microvasc Res 67:9-17

7. Ciarimboli G, Hjalmarsson C, Bokenkamp A, Schurek HJ, Haraldsson B (2003) Dynamic alterations of glomerular charge density in fixed rat kidneys suggest involvement of endothelial cell coat. Am J Physiol Renal Physiol 285: F722-F730

8. Ohlson M, Sörensson J, Haraldsson B (2001) A gel-membrane model of glomerular charge and size selectivity in series. Am J Physiol Renal Physiol 280:F396-F405
9. Jeansson M, Haraldsson B (2003) Glomerular size and charge selectivity in the mouse after exposure to glucosaminoglycandegrading enzymes. J Am Soc Nephrol 14:1756-1765

10. Bjornson A, Moses J, Ingemansson A, Haraldsson B, Sorensson J (2005) Primary human glomerular endothelial cells produce proteoglycans, and puromycin affects their posttranslational modification. Am J Physiol Renal Physiol 288:F748-F756

11. Avasthi PS, Koshy V (1988) Pathophysiology and clinical relevance of proteinuria: glomerular endothelial glycocalyx. Contrib Nephrol 68:104-113

12. Deen WM (2004) What determines glomerular capillary permeability? J Clin Invest 114:1412-1414

13. Deckert T, Kofoed-Enevoldsen A, Vidal P, Norgaard K, Andreasen HB, Feldt-Rasmussen B (1993) Size- and charge selectivity of glomerular filtration in type 1 (insulin-dependent) diabetic patients with and without albuminuria. Diabetologia 36:244-251

14. Friedman S, Jones HW 3rd, Golbetz HV, Lee JA, Little HL, Myers BD (1983) Mechanisms of proteinuria in diabetic nephropathy. II. A study of the size-selective glomerular filtration barrier. Diabetes 32(Suppl 2):40-46

15. Nakamura Y, Myers BD (1988) Charge selectivity of proteinuria in diabetic glomerulopathy. Diabetes 37:1202-1211

16. Tomlanovich S, Deen WM, Jones HW 3rd, Schwartz HC, Myers BD (1987) Functional nature of glomerular injury in progressive diabetic glomerulopathy. Diabetes 36:556-565

17. Bangstad HJ, Kofoed-Enevoldsen A, Dahl-Jorgensen K, Hanssen KF (1992) Glomerular charge selectivity and the influence of improved blood glucose control in type 1 (insulin-dependent) diabetic patients with microalbuminuria. Diabetologia 35:1165-1169

18. Pietravalle P, Morano S, Cristina G et al (1991) Charge selectivity of proteinuria in type I diabetes explored by Ig subclass clearance. Diabetes 40:1685-1690

19. Deckert T, Feldt-Rasmussen B, Djurup R, Deckert M (1988) Glomerular size and charge selectivity in insulin-dependent diabetes mellitus. Kidney Int 33:100-106

20. Scandling JD, Myers BD (1992) Glomerular size-selectivity and microalbuminuria in early diabetic glomerular disease. Kidney Int $41: 840-846$

21. Lemley KV, Blouch K, Abdullah I et al (2000) Glomerular permselectivity at the onset of nephropathy in type 2 diabetes mellitus. J Am Soc Nephrol 11:2095-2105

22. Andersen S, Blouch K, Bialek J, Deckert M, Parving HH, Myers BD (2000) Glomerular permselectivity in early stages of overt diabetic nephropathy. Kidney Int 58:2129-2137

23. Torffvit O, Rippe B (1999) Size and charge selectivity of the glomerular filter in patients with insulin-dependent diabetes mellitus: urinary immunoglobulins and glycosaminoglycans. Nephron 83:301-307

24. Osicka TM, Pratt LM, Comper WD (1996) Glomerular capillary wall permeability to albumin and horseradish peroxidase. Nephrology 2:199-212

25. Ohlson M, Sörensson J, Haraldsson B (2000) Glomerular size and charge selectivity in the rat as revealed by FITC-Ficoll and albumin. Am J Physiol Renal Physiol 279:F84-F91

26. Johnsson E, Haraldsson B (1992) An isolated perfused rat kidney preparation designed for assessment of glomerular permeability characteristics. Acta Physiol Scand 144:65-73

27. Vernier RL, Steffes MW, Sisson-Ross S, Mauer SM (1992) Heparan sulfate proteoglycan in the glomerular basement membrane in type 1 diabetes mellitus. Kidney Int 41:1070-1080

28. Tamsma JT, van den Born J, Bruijn JA et al (1994) Expression of glomerular extracellular matrix components in human diabetic nephropathy: decrease of heparan sulphate in the glomerular basement membrane. Diabetologia 37:313-320

29. Reddi AS, Ramamurthi R, Miller M, Dhuper S, Lasker N (1991) Enalapril improves albuminuria by preventing glomerular loss of 
heparan sulfate in diabetic rats. Biochem Med Metab Biol 45:119-131

30. Wu VY, Wilson B, Cohen MP (1987) Disturbances in glomerular basement membrane glycosaminoglycans in experimental diabetes. Diabetes 36:679-683

31. Conde-Knape K (2001) Heparan sulfate proteoglycans in experimental models of diabetes: a role for perlecan in diabetes complications. Diabetes Metab Res Rev 17:412-421

32. Rossi M, Morita H, Sormunen R et al (2003) Heparan sulfate chains of perlecan are indispensable in the lens capsule but not in the kidney. EMBO J 22:236-245

33. Rippe B, Haraldsson B (1994) Transport of macromolecules across microvascular walls: the two-pore theory. Physiol Rev $74: 163-219$

34. Makino S, Kunimoto K, Muraoka Y, Mizushima Y, Katagiri K, Tochino Y (1980) Breeding of a non-obese, diabetic strain of mice. Jikken Dobutsu 29:1-13

35. Craighead JE (1980) Experimental models of juvenile onset (insulin-dependent) diabetes mellitus. Monogr Pathol 21:166-176

36. Maeda M, Yabuki A, Suzuki S, Matsumoto M, Taniguchi K, Nishinakagawa H (2003) Renal lesions in spontaneous insulindependent diabetes mellitus in the nonobese diabetic mouse: acute phase of diabetes. Vet Pathol 40:187-195

37. Doi T, Hattori M, Agodoa LY et al (1990) Glomerular lesions in nonobese diabetic mouse: before and after the onset of hyperglycemia. Lab Invest 63:204-212

38. Hryciw DH, Lee EM, Pollock CA, Poronnik P (2004) Molecular changes in proximal tubule function in diabetes mellitus. Clin Exp Pharmacol Physiol 31:372-379

39. Esmann M, Skou JC (1988) Temperature-dependencies of various catalytic activities of membrane-bound $\mathrm{Na}+/ \mathrm{K}+$-ATPase from ox brain, ox kidney and shark rectal gland and of C12E8-solubilized shark $\mathrm{Na}+/ \mathrm{K}+-$-ATPase. Biochim Biophys Acta 944:344-350

40. Charnoch JS, Doty DM, Russel JC (1971) The effect of temperature on the activity of $\mathrm{Na}+/ \mathrm{K}+$-ATPase. Arch Biochem Biophys 142:633-637

41. Sörensson J, Ohlson M, Haraldsson B (2001) A quantitative analysis of the glomerular charge barrier in the rat. Am J Physiol Renal Physiol 280:F646-F656

42. Hjalmarsson C, Ohlson M, Haraldsson B (2001) Puromycin aminonucleoside damages the glomerular size barrier with minimal effects on charge density. Am J Physiol Renal Physiol 281:F503-F512

43. Jeansson M, Haraldsson B (2006) Morphological and functional evidence for an important role of the endothelial cell glycocalyx in the glomerular barrier. Am J Physiol Renal Physiol 290: F111-F116

44. Iozzo RV (1998) Matrix proteoglycans: from molecular design to cellular function. Annu Rev Biochem 67:609-652

45. Border WA, Noble NA, Yamamoto T, Tomooka S, Kagami S (1992) Antagonists of transforming growth factor-beta: a novel approach to treatment of glomerulonephritis and prevention of glomerulosclerosis. Kidney Int 41:566-570

46. Border WA, Noble NA, Yamamoto T et al (1992) Natural inhibitor of transforming growth factor-beta protects against scarring in experimental kidney disease. Nature 360:361-364

47. Hildebrand A, Romaris M, Rasmussen LM et al (1994) Interaction of the small interstitial proteoglycans biglycan, decorin and fibromodulin with transforming growth factor beta. Biochem J 302:527-534

48. Mogyorosi A, Ziyadeh FN (1998) Increased decorin mRNA in diabetic mouse kidney and in mesangial and tubular cells cultured in high glucose. Am J Physiol 275:F827-F832 